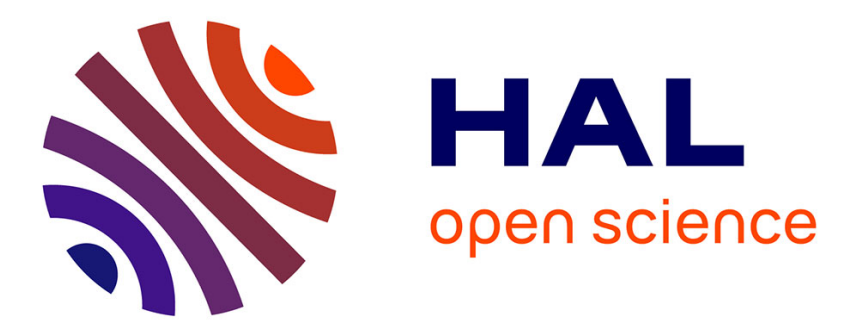

\title{
Experimental evidence of the double-porosity effects in geomaterials
}

\author{
Tien Dung Tran Ngoc, Jolanta Lewandowska, Henri Bertin
}

\section{To cite this version:}

Tien Dung Tran Ngoc, Jolanta Lewandowska, Henri Bertin. Experimental evidence of the doubleporosity effects in geomaterials. Acta Geophysica, 2014, 62 (3), pp.642-655. 10.2478/s11600-0130198-x . hal-02092974

\section{HAL Id: hal-02092974 \\ https://hal.science/hal-02092974}

Submitted on 8 Apr 2019

HAL is a multi-disciplinary open access archive for the deposit and dissemination of scientific research documents, whether they are published or not. The documents may come from teaching and research institutions in France or abroad, or from public or private research centers.
L'archive ouverte pluridisciplinaire HAL, est destinée au dépôt et à la diffusion de documents scientifiques de niveau recherche, publiés ou non, émanant des établissements d'enseignement et de recherche français ou étrangers, des laboratoires publics ou privés. 


\title{
Experimental Evidence of the Double-Porosity Effects in Geomaterials
}

\author{
Tien Dung TRAN NGOC ${ }^{1,2}$, Jolanta LEWANDOWSKA ${ }^{3}$, \\ and Henri BERTIN ${ }^{4}$ \\ ${ }^{1}$ Institut National de la Recherche Scientifique, \\ Centre Eau Terre Environnement (INRS-ETE), Québec, Canada \\ e-mail: tien_dung.tran_ngoc@ete.inrs.ca (corresponding author)
}

${ }^{2}$ Faculty of Environment, Ho Chi Minh City University of Technology (HCMUT)/

Centre Asiatique de Recherche sur l'Eau (CARE), Ho Chi Minh City, Vietnam;

e-mail: tdung.tranngoc@yahoo.ca

${ }^{3}$ Laboratoire de Mécanique et Génie Civil (LMGC), Montpellier, France

e-mail: jolanta.lewandowska@univ-montp2.fr

${ }^{4}$ Laboratoire I2M-TREFLE Université de Bordeaux, Bordeaux, France e-mail: h.bertin@i2m.u-bordeaux1.fr

\begin{abstract}
Double-porosity is an important characteristic of microstructure in a large range of geomaterials. It designs porous media with connected fissures/fractures or aggregated soils. The origin of double-porosity can be natural or/and it can result from mechanical, chemical or biological damage. The presence of double-porosity can significantly affect the behaviour of geomaterials. In this paper we provide an experimental evidence of the double-porosity effects by performing laboratory experiments. Series of tracer dispersion experiments (in saturated and unsaturated steady-state water flow conditions) in a physical model of double-porosity geomaterial were carried out. For the comparative purposes, experiments of the same type were also performed in a singleporosity model medium. The results clearly showed that the doubleporosity microstructure leads to the non-Fickian behaviour of the tracer (early breakthrough and long tail) in both saturated and unsaturated cases.
\end{abstract}

Key words: double-porosity, physical model, unsaturated/saturated conditions, tracer dispersion, non-Fickian behaviour. 


\section{INTRODUCTION}

Geomaterials are very often heterogeneous formations. They are named "double-porosity" structures, when showing strong contrast between characteristic pore sizes at microscopic or REV (Representative Elementary Volume) scale, as for example in the case of fractured/fissured porous rocks or aggregated soils. The origin of double porosity can be natural or/and it can result from mechanical, chemical or biological damage. The presence of double-porosity can significantly affect the behaviour of geomaterials. From the point of view of transfer/transport processes it is generally believed that double-porosity is responsible for local non-equilibrium conditions due to local mass exchanges. It leads to non-Fickian behaviour, preferential transfer/transport and tailing observed in the breakthrough curves. A great number of theoretical (or conceptual) models describing such a behaviour has been developed in the literature since the first pioneer papers by Barenblatt et al. (1960) and Warren and Root (1963).

In general, the non-Fickian behaviour can result from many different causes, other than the double-porosity microstructure. So far, various aspects of this complex problem have been investigated in many publications, for example: Scheidegger (1958), Elrick and French (1966), Cassel et al. (1975), van Genuchten and Wierenga (1977), Matheron and de Marsily (1980), Rao et al. (1980), Nkedi-Kizza et al. (1983), Seyfried and Rao (1987), Silliman and Simpson (1987), Koch and Fluhler (1993), Gaber et al. (1995), Sternberg et al. (1996), Delay et al. (1997), Carrera et al. (1998), Berkowitz et al. (2000), Katterer et al. (2001), Levy and Berkowitz (2003), Haws et al. (2004), Zinn et al. (2004), Knudby and Carrera (2005), Pot et al. (2005), Köhne et al. (2006, 2009), Carminati et al. (2008), Gouze et al. (2008), Willmann et al. (2008), Fourar and Radilla (2009), Le Goc et al. (2010), Dentz et al. (2011), Koestel et al. (2012), Bijeljic et al. (2013) and others.

Very often the interpretation of experimental data concerning the nonFickian behaviour, preferential transfer/transport and tailing effect appears very difficult. In natural systems, different effects (of physical, chemical or biological nature), are superposed. One way to overcome this difficulty seems to be the development of physical models in which the double porosity microstructure is the only source of the anomalous behavior. For example, in Lewandowska et al. (2005, 2008), Tran Ngoc et al. (2007, 2011), and Szymkiewicz et al. (2008), a physical model of double-porosity was used to investigate the water flow in saturated and unsaturated conditions, and to validate a mathematical model obtained by periodic homogenization.

The main objective of the study presented in this paper is to provide the experimental evidence of the anomalous dispersion due to the doubleporosity microstructure. For this purpose, several dispersion experiments of 
conservative tracer $(\mathrm{NaCl})$ in single- and double-porosity media under saturated and unsaturated steady-state water flow conditions were conducted.

\section{EXPERIMENTS}

\subsection{Double-porosity physical model}

The materials which were employed to build the physical model of doubleporosity consisted of fine sand and solidified clay spheres. The spheres were distributed periodically in the sandy matrix, forming central cubic type of arrangement. The average diameter of spheres after solidification is $6.4 \mathrm{~mm}$. The sand is Hostun HN38 (Flavigny et al. 1990) and the clay comes from La Bisbal, North-East Spain. The physical and hydraulic properties of these two materials were previously investigated by Lewandowska et al. (2005, 2008), Szymkiewicz et al. (2008), and Tran Ngoc et al. (2011). The saturated hydraulic conductivity of the Hostun sand and clay material are about $3 \times 10^{-5}$ and $2 \times 10^{-8} \mathrm{~m} / \mathrm{s}$, respectively, determined from both infiltrometer and pumppressure device. Note that the obtained clay conductivity at saturation was comparable to the value derived from mercury injection data (Daian 2007). The grain-size distribution of sand is relatively uniform with mean diameter

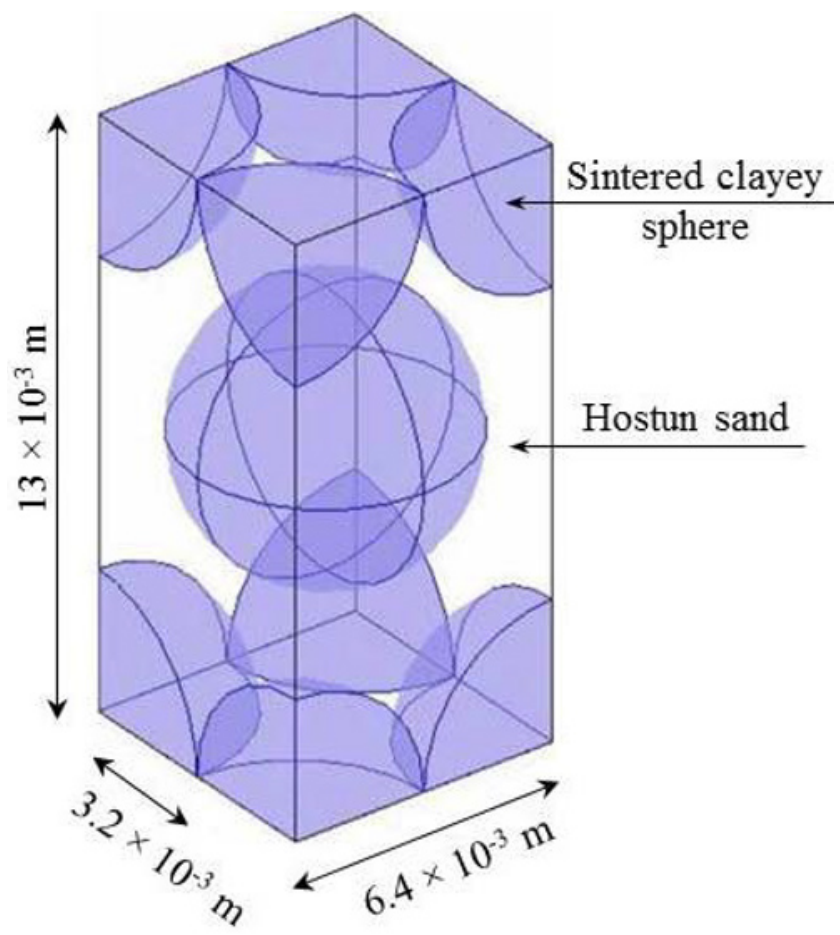

Fig. 1. Microstructure of the double-porosity medium. 
$d_{50}=162 \mu \mathrm{m}$. Its chemical composition is mainly quartz. According to mercury injection analysis the average pore-size in clay spheres is around $0.7 \mu \mathrm{m}$. We estimate that the ratio of characteristic pore sizes of sand and clay spheres is of the order of 1:250. The double-porosity model was built in a column, by putting alternatively a layer of spheres and a layer of sand, and then mechanically compacting the two layers. By scrupulously following the established procedure, the periodic structure was obtained. In each layer of spheres, each sphere touches the neighbouring spheres in four contact points (Fig. 1). The height of the microstructure period is around $13 \mathrm{~mm}$.

\subsection{Experimental apparatus}

The tracer dispersion experiments were independently conducted in the three media: (i) sand, (ii) solidified clay, and (iii) double-porosity medium (Table 1). The experiments in sand and in double-porosity medium were performed in a Plexiglas column whose height is $60 \mathrm{~cm}$ (the medium height is $\sim 50 \mathrm{~cm}$ ) and inner diameter of $6 \mathrm{~cm}$, whereas a cylinder with $25.9 \mathrm{~cm}$ of height and $5.25 \mathrm{~cm}$ of diameter was used for the experiments in the solidified clay. In the latter case, the cylinder was wrapped up by a rubber membrane and covered by plastic gel to ensure the containment. The vertical water flow was controlled by inflow rate (peristaltic pump) and outflow rate (balance). The water content inside the medium was locally measured by

Table 1

Characteristics of single- and double-porosity media

\begin{tabular}{|l|c|c|c|c|c|c|c|}
\hline Test & Medium & Height $L[\mathrm{~cm}]$ & $w_{1}$ & $w_{2}$ & $n_{1}$ & $n_{2}$ & $S$ \\
\hline \multicolumn{7}{|c|}{ Saturated condition } \\
\hline 1 & Sand & 50.1 & & & 0.399 & & 1 \\
2 & Double-porosity & 50.3 & 0.483 & 0.517 & 0.386 & 0.343 & 1 \\
3 & Clay & 25.9 & & & & 0.343 & 1 \\
\hline \multicolumn{7}{|c|}{ Unsaturated condition } \\
\hline 4 & Sand & 50.3 & & & 0.404 & & 0.86 \\
5 & Sand & 50.2 & & & 0.400 & & 0.87 \\
6 & Double-porosity & 51.0 & 0.490 & 0.510 & 0.378 & 0.343 & 0.88 \\
7 & Double-porosity & 46.9 & 0.483 & 0.517 & 0.386 & 0.343 & \\
8 & Double-porosity & 51.0 & 0.490 & 0.510 & 0.378 & 0.343 & 0.82 \\
\hline
\end{tabular}

Explanations: $w_{1}$ and $w_{2}$ - volumetric fraction of sand and clay; $n_{1}$ - porosity of sand measured by gravimetry; $n_{2}$ - porosity of clayey spheres measured by gamma ray attenuation technique; $S$ - saturation degree, $S=\theta / n ; \theta$ - average water content measured by gamma ray attenuation technique; $n$ - average porosity, $n=w_{1} n_{1}+w_{2} n_{2}$. 
gamma rays attenuation technique (Tran Ngoc 2008). Salt ( NaCl) solutions with concentrations of 5 and $20 \mathrm{~g} / 1$ were used as a tracer. The breakthrough concentrations were measured every $300 \mathrm{~s}$ by means of a densitometer (Anton Paar, $\mathrm{mP} 200$ ). The relative concentration is expressed by

$$
\frac{C}{C_{0}}=\frac{\rho(t)-\rho_{\min }}{\rho_{\max }-\rho_{\min }},
$$

where $C\left[\mathrm{M} / \mathrm{L}^{3}\right]$ is the measured concentration in the BTC evolution at the outlet, $C_{0}\left[\mathrm{M} / \mathrm{L}^{3}\right]$ is the reference concentration, $\rho(t), \rho_{\min }$ and $\rho_{\max }\left[\mathrm{M} / \mathrm{L}^{3}\right]$ are the measured densities with time, minimal and maximal, respectively. Note that the density measurement precision is of 0.0005 .

The experimental conditions were isothermal, and at relatively high water saturation (i.e., the water saturation degree varied between 0.82 and 1 ).

\subsection{Experimental procedure}

The experimental procedure consisted of three steps: (i) preparing a sample of single- or double-porosity medium, (ii) establishing saturated or unsaturated water flow, and (iii) launching tracer dispersion (Tran Ngoc et al. 2007). The main parameters of the experiments are presented in Tables 1 and 2. For the experiments in saturated conditions, several pore volumes of $\mathrm{CO}_{2}$ were first injected into the initially dry medium, and then the $\mathrm{NaCl}$ solution was pumped from the bottom of the column to saturate the medium completely (Tests 1-3). For the experiments in unsaturated conditions, the pure water or tracer solution was injected from the column bottom, until steadystate unsaturated flow was obtained. The unsaturated conditions of Test 8 were obtained in a different way than those of Tests 4-7. In Test 8, the double-porosity medium was at first saturated and drained by applying a suction

Table 2

Experimental conditions

\begin{tabular}{|c|c|c|c|c|c|}
\hline Test & Medium & $\begin{array}{c}\text { Concentration } \\
C(t<0)[\mathrm{g} / \mathrm{l}]\end{array}$ & $\begin{array}{c}\text { Concentration } \\
C(t \geq 0)[\mathrm{g} / \mathrm{l}]\end{array}$ & $\begin{array}{c}\text { Darcy flux } \\
q[\mathrm{~cm} / \mathrm{s}]\end{array}$ & $\begin{array}{c}\text { Temperature } \\
T\left[{ }^{\circ} \mathrm{C}\right]\end{array}$ \\
\hline 1 & Sand & 20 & $z=L, C=0$ & $5.90 \times 10^{-4}$ & $19.9-19.3$ \\
2 & Double-porosity & 20 & $z=L, C=0$ & $5.90 \times 10^{-4}$ & $19.1-19.5$ \\
3 & Clay & 20 & $z=L, C=0$ & $1.28 \times 10^{-4}$ & $24.5-24.7$ \\
4 & Sand & 0 & $z=L, C=5$ & $3.44 \times 10^{-4}$ & $20.4-21.5$ \\
5 & Sand & 0 & $z=L, C=5$ & $3.44 \times 10^{-4}$ & $20.9-22.8$ \\
6 & Double-porosity & 0 & $z=L, C=5$ & $3.44 \times 10^{-4}$ & $20.5-22.2$ \\
7 & Double-porosity & 0 & $z=L, C=5$ & $3.44 \times 10^{-4}$ & $20.2-20.4$ \\
8 & Double-porosity & 5 & $z=0, C=0$ & $3.44 \times 10^{-4}$ & $19.9-20.3$ \\
\hline
\end{tabular}


of $-85 \mathrm{~cm}$ at the column bottom, and then the steady-state unsaturated flow was established by pumping the solution from the column top. The experiments of $\mathrm{NaCl}$ transport with stepwise concentration input started by switching the four-lines valve to change the displacing substance (solution or pure water) from the column bottom for Tests 1-7 and from the column top for Test 8 .

\section{RESULTS AND DISCUSSION}

The first experimental results concern water saturation profiles, since water content inside the column was measured before each experiment. The second results are tracer concentration curves versus time. Concentration at the outlet of the column was monitored during each experiment. In order to compare the single-porosity and the double-porosity media, two cases were analyzed separately:

口 saturated conditions,

口 unsaturated conditions.

In order to enable the comparative analysis, the BTC data of Tests 2 and 8 (Table 1) were subjected to conversion from "depollution" to "pollution" type experiment by plotting the quantity $\left(1-C / C_{0}\right)-$ see details in Tran Ngoc (2008). This transformation seems delicate and can introduce an error of interpretation.

\subsection{Saturated case}

In Figure 2 the distribution of water content, as measured by gamma ray attenuation technique, for three porous materials, namely: sand (Test 1), double-porosity (Test 2), and solidified clay (Test 3), is shown. It can be seen that the water content profile in the double-porosity medium is more dispersed that in the sand (the single-porosity medium). It is believed that this effect is related to the presence of layers of clay spheres. The results for the column made of solidified clay show that there exists a local heterogeneity in the column: the water profile depends on the measurement direction and a local peak value was detected. In Figure 3 three tracer breakthrough curves for all three materials are drawn. The complete saturation of sand and solidified clay samples is confirmed by the fact that the ratio $C / C_{0}=0.5$ is obtained for $V / V_{p}=1$ where $V\left[\mathrm{~L}^{3}\right]$ is the volume of displaced fluids (water or brine solution), and $V_{p}\left[\mathrm{~L}^{3}\right]$ is the volume of pores in the sample (thus $V / V_{p}$ is defined as the relative time corresponding to the travel time of the tracer after injection at the inlet). The curves for sand (Test 1 ) and solidified clay (Test 3) are symmetrical, while the curve for the double-porosity medium (Test 2) shows the non-Fickian characteristics. It can be concluded that clay inclusions in sandy matrix make the concentration at the outlet of the column to decrease more dramatically than in pure sand. We also observe a retarda- 


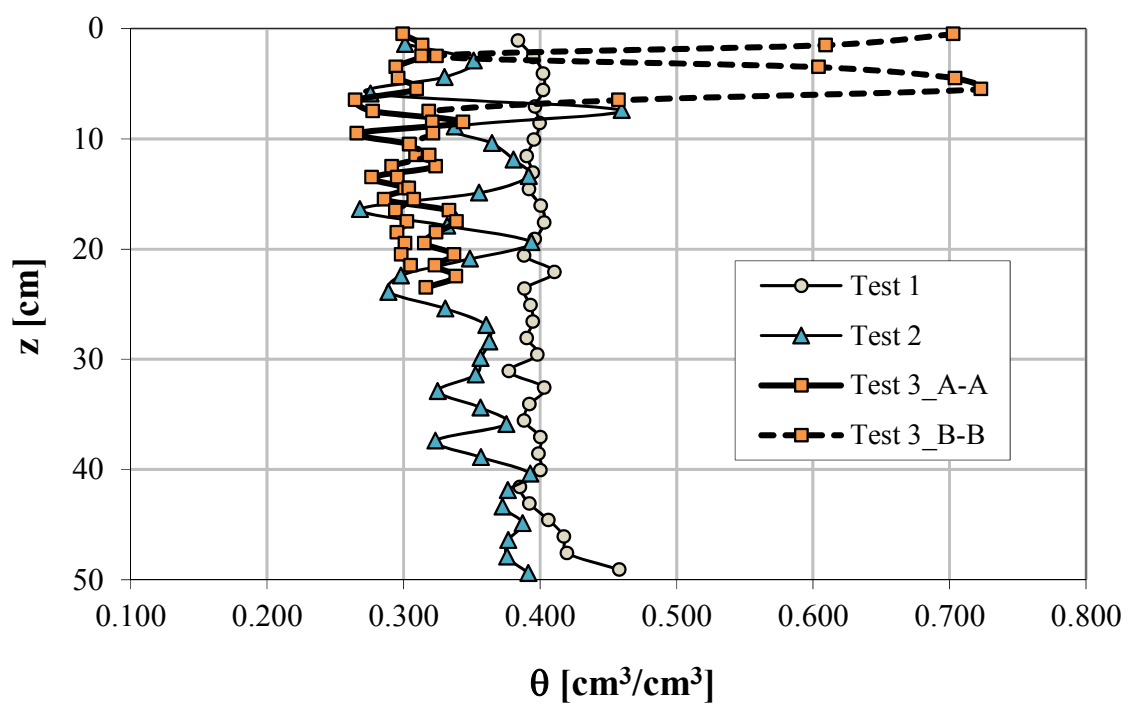

Fig. 2. Water content profiles measured locally by gamma ray attenuation technique for three saturated media: sand (Test 1), double-porosity medium (Test 2 ), and solidified clay (Test 3 ). A-A - profile measured along a sample axes, B-B - profile which is perpendicular to A-A.

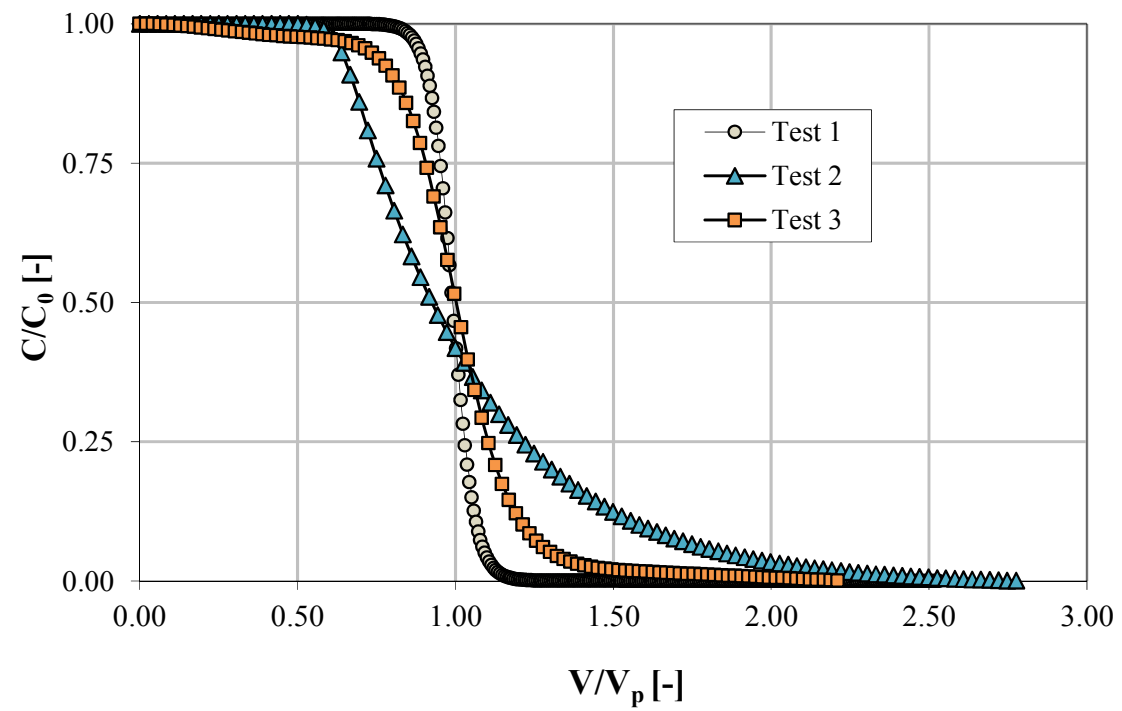

Fig. 3. Evolution of the tracer breakthrough versus relative time $V / V_{p}$ for three saturated media: sand (Test 1), double-porosity medium (Test 2 ), and solidified clay (Test 3 ). $V / V_{p}$ is the ratio of volume of water to the pore volume. 
tion (tail) effect at long time: the concentration is slowly decreasing over more than $2.5 V_{\mathrm{p}}$.

\subsection{Unsaturated case}

We considered the measurement of water content and water flux at the outlet of the column as a global criterion of the permanent unsaturated water flow. It was observed that the outlet water flux was slightly less than the inlet flux, which could be due to degasing air from the medium. The measured average water contents of the unsaturated single- and double-porosity media after dispersion test are presented in Fig. 4. The tracer breakthrough curves are presented in Fig. 5. The behaviour of tracer in sand is as expected for a single-porosity medium under unsaturated conditions, i.e., $C / C_{0}=0.5$ is obtained for $V / V_{p}<1$. On the contrary, the breakthrough curves for the doubleporosity medium (obtained in the same conditions of water flow as in case of sample porosity medium) show an earlier arrival of concentration (at $V / V_{p}$ $<0.5$ ) and a long tail effect. As in the saturated case, the double-porosity medium shows the non-Fickian behaviour.

Finally, in Fig. 6 the comparison of all breakthrough curves (for saturated and unsaturated cases) obtained for the double-porosity medium is presented. For the case with the lowest saturation (Test 8, Table 1), the arrival of detectable signal was the earliest (Fig. 6b). The normalized arrival time $V / V_{p}$ of first $5 \%$ of the relative concentration $C / C_{0}$ (Knudby and Carrera 2005) decreased with lower water saturation: about $0.60,0.59,0.51$, and 0.43 for Tests $2,6,7$, and 8 , respectively. These relative $5 \%$ arrival times were longer than ones (0.2-0.3) observed in a great number of literature breakthrough experiments in undisturbed soils, reviewed by Koestel et al. (2012). Remember that our experiments were carried out under the conditions close to the full saturation (Table 1). Based on the trend observed in Fig. 6 , the faster $5 \%$ arrival time would be expected in the order of 0.25 , even less for experiments with low saturation. As it can be seen, the BTC curves for the double-porosity media present non-Fickian characteristics independently of the saturation degree: (i) non symmetrical curves, (ii) early breakthrough, and (iii) tail effect. We can distinguish two types of tendency at early and at long times, as a function of water content: (i) the breakthrough occurs slightly earlier for less saturated medium (see Fig. $6 \mathrm{~b}$ for clearer), and (ii) the tail is longer for a more saturated medium. The latter effect is very well pronounced.

Finally, it has to be underlined that the distribution of water in the double-porosity medium is very heterogeneous (Fig. 4). It is related to the double-porosity periodic structure but can also result from, for example, the local non equilibrium of water pressure. Therefore, it should be investigated in the future tests. 


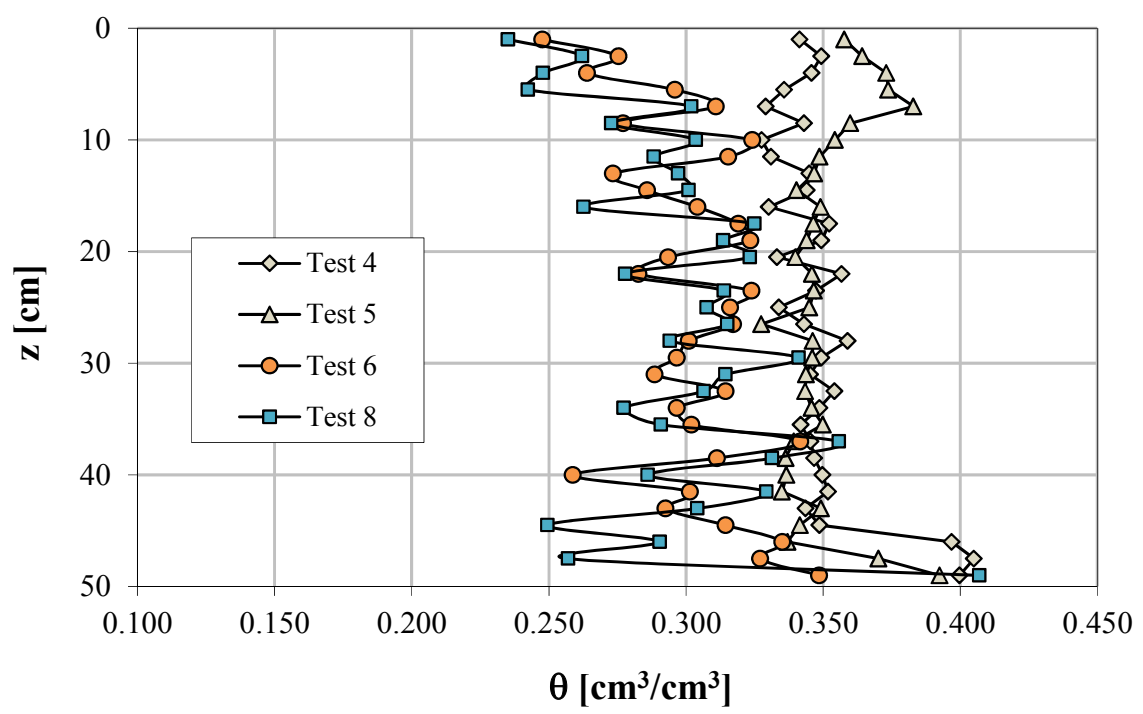

Fig. 4. Water content profiles measured locally by gamma ray attenuation technique after the end of dispersion test for the unsaturated media: sand (Tests 4 and 5), and double-porosity medium (Tests 6 and 8). This figure is reprinted from Tran Ngoc et al. (2011) with permission.

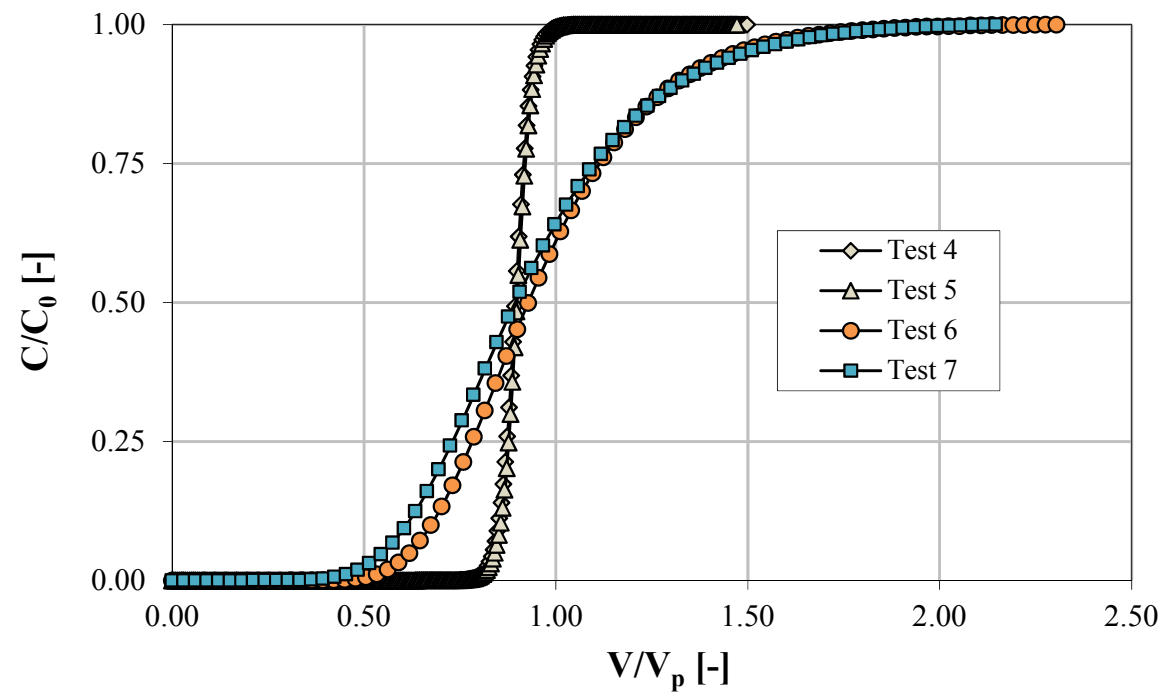

Fig. 5. Evolution of the tracer breakthrough versus time for three unsaturated media: sand (Tests 4 and 5), double-porosity medium (Tests 6 and 7), and $V / V_{p}$ is the ratio of volume of water to the pore volume. This figure is reprinted from Tran Ngoc et al. (2011) with permission. 

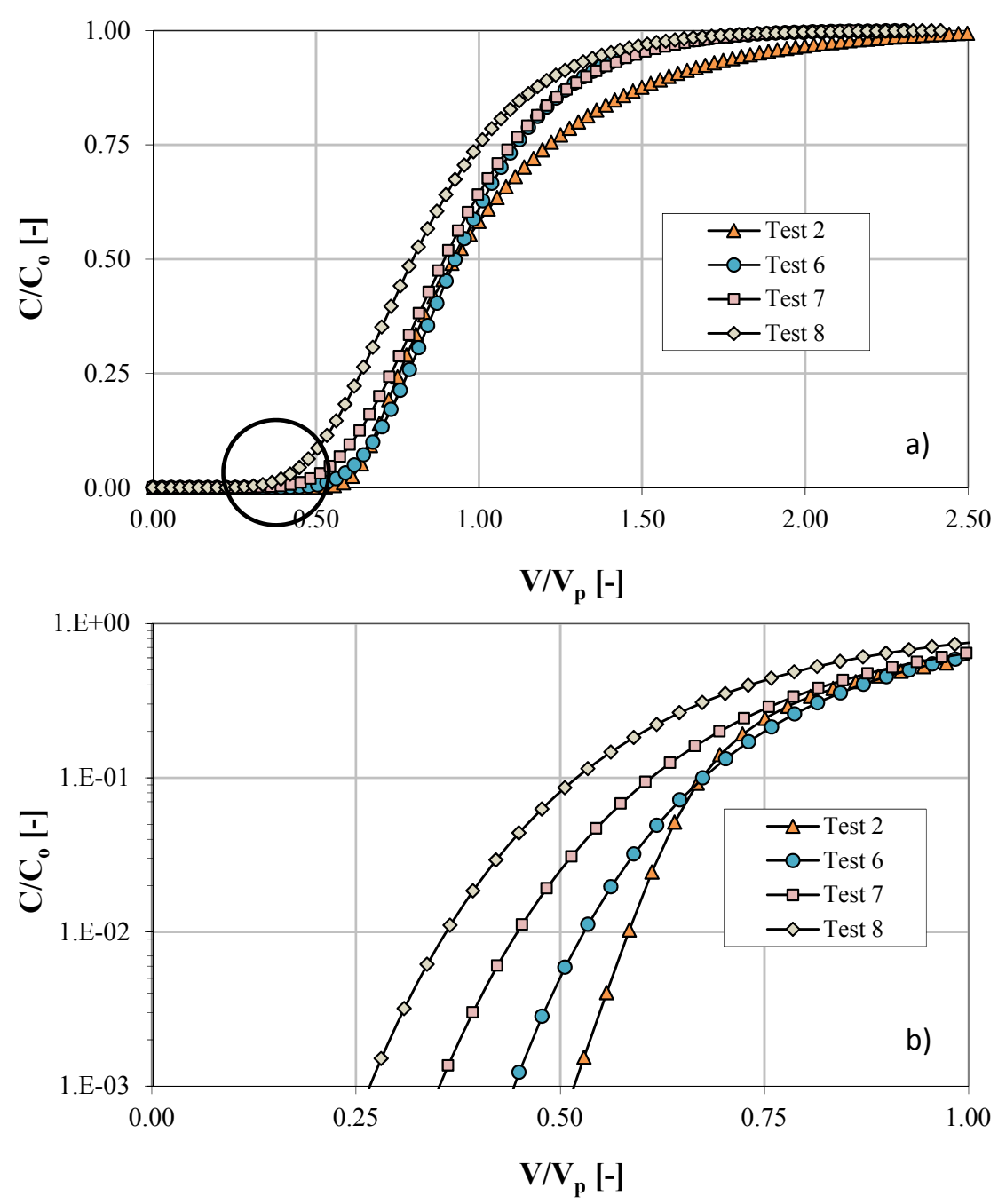

Fig. 6. Evolution of the tracer breakthrough versus time for the saturated (Test 2) and unsaturated (Tests 6-8) double-porosity media: (a) linear graph, and (b) semi-log graph for the relative concentration enabling to observe earlier breakthroughs in the zoom of the figure (a). Note that the precision of detectable concentration is equivalent to the relative concentration at the order of $1 \times 10^{-3} . V / V_{p}$ is the ratio of volume of water to the pore volume.

\section{CONCLUSION}

The qualitative analysis of the results of dispersion tests carried out in the physical model of double-porosity medium showed non-Fickian behaviour in both saturated and unsaturated water flow conditions. In all cases the 
breakthrough curves are non-symmetrical, the tracer arrival is accelerated and there is a long-tail in the concentration distribution curves.

The experimental results reported in this paper can be used to validate different theoretical models for double-porosity/dual-permeability media proposed in the literature or new ones. The laboratory dispersion tests presented in this paper can also be considered as a non-destructive method of detection of the double-porosity structure in geomaterials.

Acknowledgements. We would like to thank the CNRS (Centre National de la Recherche Scientifique - French National Research Center) for a doctoral fellowship granted to the first author. This research was financially supported by the GDR "Hydrodynamique et Transferts dans les Hydrosystèmes Souterrains", France. We also appreciate the constructive suggestions of the anonymous reviewers.

\section{References}

Barenblatt, G., I. Zheltov, and I. Kochina (1960), Basic concepts in the theory of seepage of homogeneous liquids in the fissured rocks, J. Appl. Math. Mech. 24, 5, 1286-1303, DOI: 10.1016/0021-8928(60)90107-6.

Berkowitz, B., H. Scher, and S.E. Silliman (2000), Anomalous transport in laboratory-scale, heterogeneous porous media, Water Resour. Res. 36, 1, 149-158, DOI: 10.1029/1999WR900295.

Bijeljic, B., P. Mostaghimi, and M.J. Blunt (2013), Insights into non-Fickian solute transport in carbonates, Water Resour. Res. 49, 5, 2714-2728, DOI: 10.1002/wrcr.20238.

Carminati, A., A. Kaestner, P. Lehmann, and H. Flühler (2008), Unsaturated water flow across soil aggregate contacts, Adv. Water Resour. 31, 9, 1221-1232, DOI: 10.1016/j.advwatres.2008.01.008.

Carrera, J., X. Sánchez-Vila, I. Benet, A. Medina, G. Galarza, and J. Guimerà (1998), On matrix diffusion: formulations, solution methods and qualitative effects, Hydrogeol. J. 6, 1, 178-190, DOI: 10.1007/s100400050143.

Cassel, D.K., M.T. van Genuchten, and P.J. Wierenga (1975), Predicting anion movement in disturbed and undisturbed soils, Soil Sci. Soc. Am. J. 39, 6, 1015-1019, DOI: 10.2136/sssaj1975.03615995003900060008x.

Daïan, J.-F. (2007), Mercury porometry - XDQ model, Université Joseph Fourier, Grenoble, 97 pp., http://www.lthe.fr/LTHE3/IMG/pdf/Le-Modele-XDQ.pdf (in French).

Delay, F., G. Porel, and G. de Marsily (1997), Predicting solute transport in heterogeneous media from results obtained in homogeneous ones: An 
experimental approach, J. Contam. Hydrol. 25, 1-2, 63-84, DOI: 10.1016/ S0169-7722(96)00020-4.

Dentz, M., T. Le Borgne, A. Englert, and B. Bijeljic (2011), Mixing, spreading and reaction in heterogeneous media: A brief review, J. Contam. Hydrol. 120121, 1-17, DOI: 10.1016/j.jconhyd.2010.05.002.

Elrick, D.E., and L.K. French (1966), Miscible displacement patterns on disturbed and undisturbed soil cores, Soil Sci. Soc. Am. J. 30, 2, 153-156, DOI: 10.2136/sssaj1966.03615995003000020007x.

Flavigny, E., J. Desrues, and B. Palayer (1990), Note technique - Le sable d'Hostun “'RF', Rev. Fr. Geotech. 53, 67-70 (in French).

Fourar, M., and G. Radilla (2009), Non-Fickian description of tracer transport through heterogeneous porous media, Transp. Porous Med. 80, 3, 561-579, DOI: $10.1007 / \mathrm{s} 11242-009-9380-7$.

Gaber, H.M., W.P. Inskeep, J.M. Wraith, and S.D. Comfort (1995), Nonequilibrium transport of atrazine through large intact soil cores, Soil Sci. Soc. Am. J. 59, 1, 60-67, DOI: 10.2136/sssaj1995.03615995005900010009x.

Gouze, P., T. Le Borgne, R. Leprovost, G. Lods, T. Poidras, and P. Pezard (2008), Non-Fickian dispersion in porous media: 1 . Multiscale measurements using single-well injection withdrawal tracer tests, Water Resour. Res. 44, 6, W06426, DOI: 10.1029/2007wr006278.

Haws, N.W., B.S. Das, and P.S.C. Rao (2004), Dual-domain solute transfer and transport processes: evaluation in batch and transport experiments, J. Contam. Hydrol. 75, 3-4, 257-280, DOI: 10.1016/j.jconhyd.2004.07.001.

Kätterer, T., B. Schmied, K.C. Abbaspour, and R. Schulin (2001), Single- and dualporosity modelling of multiple tracer transport through soil columns: effects of initial moisture and mode of application, Eur. J. Soil Sci. 52 , 1, 25-36, DOI: 10.1046/j.1365-2389.2001.00355.x.

Knudby, C., and J. Carrera (2005), On the relationship between indicators of geostatistical, flow and transport connectivity, Adv. Water Resour. 28, 4, 405-421, DOI: 10.1016/j.advwatres.2004.09.001.

Koch, S., and H. Flühler (1993), Solute transport in aggregated porous media: Comparing model independent and dependent parameter estimation, Water Air Soil Poll. 68, 1-2, 275-289, DOI: 10.1007/Bf00479408.

Koestel, J.K., J. Moeys, and N.J. Jarvis (2012), Meta-analysis of the effects of soil properties, site factors and experimental conditions on solute transport, Hydrol Earth Syst. Sc. 16, 6, 1647-1665, DOI: 10.5194/hess-16-1647-2012.

Köhne, J.M., S. Köhne, and J. Šimůnek (2009), A review of model applications for structured soils: a) Water flow and tracer transport, J. Contam. Hydrol. 104, 1-4, 4-35, DOI: 10.1016/j.jconhyd.2008.10.002.

Köhne, S., B. Lennartz, J.M. Köhne, and J. Šimůnek (2006), Bromide transport at a tile-drained field site: experiment, and one- and two-dimensional 
equilibrium and non-equilibrium numerical modeling, J. Hydrol. 321, 1-4, 390-408, DOI: 10.1016/j.jhydrol.2005.08.010.

Le Goc, R., J.-R. de Dreuzy, and P. Davy (2010), Statistical characteristics of flow as indicators of channeling in heterogeneous porous and fractured media, Adv. Water Resour. 33, 3, 257-269, DOI: 10.1016/j.advwatres.2009.12.002.

Levy, M., and B. Berkowitz (2003), Measurement and analysis of non-Fickian dispersion in heterogeneous porous media, J. Contam. Hydrol. 64, 3-4, 203226, DOI: 10.1016/S0169-7722(02)00204-8.

Lewandowska, J., A. Szymkiewicz, W. Gorczewska, and M. Vauclin (2005), Infiltration in a double-porosity medium: Experiments and comparison with a theoretical model, Water Resour. Res. 41, 2, W02022, DOI: 10.1029/ 2004wr003504.

Lewandowska, J., T.D. Tran Ngoc, M. Vauclin, and H. Bertin (2008), Water drainage in double-porosity soils: Experiments and micro-macro modeling, J. Geotech. Geoenviron. Eng. 134, 2, 231-243, DOI: 10.1061/(ASCE)10900241(2008)134:2(231).

Matheron, G., and G. de Marsily (1980), Is transport in porous media always diffusive? A counterexample, Water Resour. Res. 16, 5, 901-917, DOI: 10.1029/ Wr016i005p00901.

Nkedi-Kizza, P., J.W. Biggar, M.T. van Genuchten, P.J. Wierenga, H.M. Selim, J.M. Davidson, and D.R. Nielsen (1983), Modeling tritium and chloride 36 transport through an aggregated oxisol, Water Resour. Res. 19, 3, 691-700, DOI: 10.1029/WR019i003p00691.

Pot, V., J. Šimůnek, P. Benoit, Y. Coquet, A. Yra, and M.-J. Martínez-Cordón (2005), Impact of rainfall intensity on the transport of two herbicides in undisturbed grassed filter strip soil cores, J. Contam. Hydrol. 81, 1-4, 63-88. DOI: $10.1016 /$ j.jconhyd.2005.06.013.

Rao, P.S.C., D.E. Rolston, R.E. Jessup, and J.M. Davidson (1980), Solute transport in aggregated porous media : Theoretical and experimental evaluation, Soil Sci. Soc. Am. J. 44, 6, 1139-1146, DOI: 10.2136/sssaj1980. $03615995004400060003 x$.

Scheidegger, A.E. (1958), The random-walk model with autocorrelation of flow through porous media, Can. J. Phys. 36, 6, 649-658, DOI: 10.1139/p58070 .

Seyfried, M.S., and P.S.C. Rao (1987), Solute transport in undisturbed columns of an aggregated tropical soil: Preferential flow effects, Soil Sci. Soc. Am. J. 51, 6, 1434-1444, DOI: 10.2136/sssaj1987.03615995005100060008x.

Silliman, S.E., and E.S. Simpson (1987), Laboratory evidence of the scale effect in dispersion of solutes in porous media, Water Resour. Res. 23, 8, 1667-1673, DOI: $10.1029 /$ WR023i008p01667.

Sternberg, S.P.K., J.H. Cushman, and R.A. Greenkorn (1996), Laboratory observation of nonlocal dispersion, Transp. Porous Media 23, 2, 135-151, DOI: 10.1007/BF00178123. 
Szymkiewicz, A., J. Lewandowska, R. Angulo-Jaramillo, and J. Butlańska (2008), Two-scale modeling of unsaturated water flow in a double-porosity medium under axisymmetric conditions, Can. Geotech. J. 45, 2, 238-251, DOI: $10.1139 / \mathrm{T} 07-096$.

Tran Ngoc, T.D. (2008), Transport de solutés dans un milieu à double-porosité non saturé. Modélisation par homogénéisation et application, Université Joseph Fourier - Grenoble, Ph.D. Thesis, 185 pp. (in French).

Tran Ngoc, T.D., J. Lewandowska, and H. Bertin (2007) Etude expérimentale de la dispersion dans un milieu à double porosité. In: 18éme Congrès Français de Mécanique, 27-31.08.2007, Grenoble, France, 6 pp. (CD-rom).

Tran Ngoc, T.D., J. Lewandowska, M. Vauclin, and H. Bertin (2011), Two-scale modeling of solute dispersion in unsaturated double-porosity media: Homogenization and experimental validation, Int. J. Numer. Anal. Meth. Geomech. 35, 14, 1536-1559, DOI: 10.1002/Nag.967.

van Genuchten, M.T., and P.J. Wierenga (1977), Mass transfer studies in sorbing porous media: II. Experimental evaluation with tritium $\left(3 \mathrm{H}_{2} \mathrm{O}\right)$, Soil Sci. Soc. Am. J. 41, 2, 272-278, DOI: 10.2136/sssaj1977.03615995004100020022x.

Warren, J.E., and P.J. Root (1963), The behavior of naturally fractured reservoirs, Soc. Pet. Eng. J. 3, 3, 245-255, DOI: 10.2118/426-PA.

Willmann, M., J. Carrera, and X. Sánchez-Vila (2008), Transport upscaling in heterogeneous aquifers: What physical parameters control memory functions? Water Resour. Res. 44, 12, W12437, DOI: 10.1029/2007wr006531.

Zinn, B., L.C. Meigs, C.F. Harvey, R. Haggerty, W.J. Peplinski, and C.F. von Schwerin (2004), Experimental visualization of solute transport and mass transfer processes in two-dimensional conductivity fields with connected regions of high conductivity, Environ. Sci. Technol. 38, 14, 3916-3926, DOI: $10.1021 / \mathrm{Es} 034958 \mathrm{~g}$.

Received 10 October 2012 Received in revised form 16 September 2013

Accepted 20 September 2013 